\title{
Processos predatórios na floresta tropical úmida da Amazônia Brasileira*
}

\author{
Philip Fearnside
}

O Instituto de Estudos Avançados da USP me convidou para falar sobre destruição ambiental na Amazônia brasileira. Trata-se, evidentemente, de um tema muito amplo, que inclui desmatamentos. $\mathrm{E}$, também, a problemática das hidroelétricas, mineração e muitas outras modalidades de destruição. Não pretenđo e, certamente, não vou conseguir falar sobre todos os tipos de destruição que temos na Amazônia. E, nem tampouco sobre outras questões que o prof. Aziz mencionou ao me apresentar, tais como a capacidade de suporte e outros temas. Quero centrar minhas observaçōes nos problemas de desmatamento da regiāo: os impactos ambientais disso decorrentes; e algumas das causas dos processos que ali atuam. E, ainda sobre que poderia ser feito para atenuar ou estancar os processos predatórios. Abordarei, obrigatoriamente, as sérias questōes envolvidas na construção das hidroelétricas. Em qualquer oportunidade, quando eu me refiro a assuntos ligados a desmatamentos, lembro que o grosso da Amazônia ainda tem o aspecto de uma imensa área florestada. Mesmo que a palestra seja sobre desmatamento, é sempre importante manter na mente que ainda existe muita floresta contínua, com mínima participação humana. Alguns diapositivos, que apresento, nos dão uma certa esperança de ter um quadro melhor; de poder conter ou reverter o quadro de destruição que vem ocorrendo, hoje, na Amazônia, mas, também, é importante lembrar que esse raciocínio tem muito de enganador. Ele pode conduzir muitas pessoas desavisadas a pensar que o desmatamento realmente nāo seja um problema tão grave assim. E, que sendo a Amazônia muito grande, onde ainda existem muitas florestas, seria praticamente impossível cortar toda a floresta. Infelizmente, esise não é o caso. A legislação que controla os desmatamentos é falha, existe muita permissividade para a continuação dos processos predatórios, e grandes interesses envolvidos na continuação do desmatamento; até que se chegue à última árvore. É a mesma coisa que aconteceu aqui no Brasil Centro-Sul, há 70 ou 80 anos passados. No Paraná, por exemplo - no início do século - o pessoal falava exatamente a mesma coisa: que a floresta era tão grande, que nunca ia se conseguir desmatar tudo. Entretanto, após algumas décadas, não existiam mais florestas por lá. O paralelismo é perfeito: o mesmo poderá acontecer na Amazônia, e, talvez com mais rapidez, se não forem tomadas medidas efetivas e de aplicação imediata. Quero lhes mostrar alguns dados sobre a marcha do desmatamento (dados já um pouco defasados) mostrando a ampliação das derrubadas, nos últimos anos, dentro de cada um dos estados e territórios, na Amazônia. Como se pode deduzir - em Mato Grosso, Rondônia e Acre - estão ocorrendo explosões de desmatamento, de forma exponencial - do tipo da inflação no Brasil - que se desdobra a cada ano. É esse o tipo de tragédia-surpresa que o desmatamento pode nos oferecer. Um tanto igual ao que as pessoas sentem quando vão para o supermercado e verificam o quanto aumentaram os preços, ou a idéia de que, com o quê, há dez anos atrás se adquirira uma casa, hoje se compra uma garrafa de Coca-Cola. Coisas assim: surpresas sucessivas, mesmo convivendo-se com a

* Transcrição da Conferência do Mês (IEA/USP): "Destruição da Amazônia", realizada no Conselho Universitário em 24/11/88. 
tendência exponencial. Esse mesmo tipo de surpresa é o que se espera, se o desmatamento conservar esse ritmo no conjunto da região amazônica.

Mato Grosso, Rondônia e Acre são os estados - na porção meridional da Amazônia - que estão recebendo o grosso dos emigrantes, provenientes do $\mathrm{Pa}$ raná, e outras áreas da metade sul do Brasil, ocorrendo uma transformação da agricultura, e uma sentida diminuição de espaços para novos agricultores. $\mathrm{O}$ café e outras culturas, que exigem muita mão-de-obra, estão sendo substituídos por cultura de soja mecanizada; por trigo, e outras culturas, que não exigem muita mão-de-obra. Avalia-se que são onze pessoas expulsas para cada uma que consegue emprego na agricultura da soja. Então, essas pessoas, ou vão para as favelas das grandes cidades - como São Paulo - ou vão para a Amazônia. É essa a situação que tem que ser revertida. Temos dados sobre Rondônia, mais recentes do que aqueles, que indicam a continuação dessa tendência exponencial. A partir de 1985, houve um pequeno achatamento do aumento da area desmatada em Rondônia. Temos um dado de 1987: a partir da imagem de satelite utilizada e interpretada por João Pomalingrow, na Itália, houve uma avaliação de que $15,1 \%$ da Rondônia estava desmatada, até o ano de 1987 . Se fosse feita uma projeção conservadora, usando os últimos dois anos de dados de satélite, seriam 17,1\% de desmatado em Rondônia, até hoje. E, fazendo esse tipo de projeção conservadora, dentro de cada um dos estados e territórios da Amazônia, referente aos últimos dois anos de dados, a área desmatada, até agora,

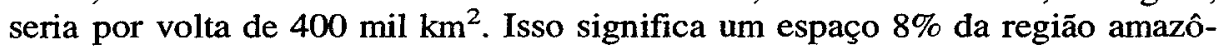
nica; quase duas vezes a área do estado de São Paulo. $\mathrm{E}$, no caso, a taxa de aumento seria $35 \mathrm{mil} \mathrm{\textrm {km } ^ { 2 }}$ ao ano; o que é uma taxa de aumento incrível. É muito maior do que a Bélgica, por exemplo, que possui somente $25 \mathrm{mil} \mathrm{km}^{2}$. Só para dar uma idéia: é o equivalente a desmatar um campo de futebol a cada cinco segundos, para se atingir a soma disso durante todo um ano. Trata-se, efetivamente, de uma taxa muito alta, que está aumentando a cada ano e, se continuar assim, em poucos anos ou dezenas de anos a floresta amazônica se extinguirá. Nessa altura, penso que é importante esclarecer os informes que vêm sendo noticiados, sobre uma divergência entre esses dados e os dados do estudo do INPE sobre queimadas, no decorrer do ano passado (1987). A reportagem que saiu na revista Veja (no 1055, de 23/11/1988), dá a manchete que é "Guerra do Fogo", como se fosse uma guerra entre mim e o Alberto Setzer do INPE, que está presente neste auditório. $\mathrm{E}$ eu acho muito importante esclarecer que não existe nenhuma guerra entre os pesquisadores. Nós estamos colaborando, tentando melhor entender o desmatamento na região. Existe divergência nos dados, e isso é uma coisa estritamente técnica; não é, em absoluto, uma questão de guerra entre os pesquisadores. Pretendo explicar o que há de diferente em termos das estimativas. A tabela do Relatório do INPE indica que a Amazônia legal, como um todo, teve $200 \mathrm{mil} \mathrm{km}$, ou 20 milhões de hectares queimados, em 1987. Agora, dentro da área considerada de florestas altas, a estimativa era de 80 mil km² , ou seja, 8 milhōes de hectares.

Existem várias razōes para se afiançar que a área desmatada realmente não é tão grande. Como eu me referi, $35 \mathrm{mil} \mathrm{km}^{2}$ são muito menos do que esses valores. Existem várias diferenças. Em primeiro lugar, esta é uma estimativa de queimadas, não de desmatamentos. É importante que se estabeleça que queimada e desmatamento são coisas diferentes; porque se queimam, também, pastagens, queima-se o cerrado, sobretudo na periferia da Amazônia. Queimam-se capoeiras. Além, evidentemente, de queimada e de derrubadas verdadeiramente novas. Então, uma grande parte do que se considerou atingido não é queimada de floresta recentemente derrubada. Isso nos autoriza a dizer que pode diminuir a avaliação dos $200 \mathrm{mil}$ para $80 \mathrm{mil} \mathrm{da}$ área total de florestas derrubadas. Existem, ainda, outros detalhes sobre os aludidos dados. Um fato a referir é que os estados de Goiás e Maranhão estão incluídos; mesmo sabendo-se que grande parte de Goiás, especialmente, está fora da Amazônia. Trata-se predominantemente de áreas ocupadas, em que grande parte dos cerrados é queimada anualmente. A não-consideração desse fato, por certo, aumentou a estimativa do 
INPE. Por outro lado, se observa que Roraima e Amapá não entram na estimativa; porque as imagens só chegavam ate o Equador. Isso pode compensar, de um lado, a estimativa exagerada feita para Mato Grosso, Rondônia, Acre, Goiás e Maranhão. No entanto, convém lembrar que as queimadas são bem maiores nessa parte da periferia sul da região do que na parte que ficou fora da imagem.

Existe um outro problema - em termos de interpretação - que $\epsilon$ o critério de como se pode medir uma área que ainda está sob a ação do fogo. No caso de Rondônia, para a qual temos dados do mesmo ano e do mesmo satélite, incluindo registro de desmatamentos. Em 1987, em Rondônia, registrou-se 18,7\% do espaço total sob a ação do fogo. Enquanto a imagem de João Pomalingrow indicou 15,1\% desmatada, ate o referido ano de 1987. Agora, se 18,7\% estava pegando fogo, isso significaria dizer que seria $40 \%$ ou mais efetivamente desmatados. $O$ nosso raciocínio parte do princípio de que não daria para queimar toda a área, todos os anos. Cada hectare só é queimado a cada dois ou três anos. Se uma pessoa possui pastagens, ela tem que reservar algum lugar para colocar o seu gado, enquanto está queimando parte de sua propriedade. Daí, porque somente se queima, cada lugar, alternadamente, de dois a três anos. Nesse caso, a diferença é muito grande entre um desmatamento nesse nível e os aludidos $15,1 \%$. A razão dessa avaliação distorcida é encontrada em certas características e atributos do próprio sensoriamento. É o problema de saturação do sensor que está em jogo: um fato que requer uma nova opção técnica. No caso da imagem de Rondônia, o desmatamento é reconhecido pela cor branca. Tudo que está em branco, dentro dessa linha vermelha, na imagem de 1987, foi incorporado como espaço total desmatado (os já aludidos 15,1\%). Esta é a Rodovia 364, que foi asfaltada pelo Projeto PMACI. Vêem-se bem as linhas de acesso para os lotes dos colonos. Cada pontinho branco na imagem representa uma quadra, de $1,1 \mathrm{~km}$ de lado. E o problema é que, quando o fogo ainda está atuando, fica registrada a temperatura do fogo alto. Esse fato pode disparar o sensor, para saturá-lo. Registra-se na imagem todo aquele pequeno espaço com pontinhos brancos, quando, na realidade, somente uma parte está sob a atuação do fogo. $E$ a somatória de tais efeitos aumenta o dado registrado, como sendo de queimadas. Então, nosso principal problema técnico reside eni conseguir fazer a coloração para esse tipo de fato. Um assunto pioneiro, que ainda está sendo desenvolvido no INPE. Não é possível registrar dados de muitos desmatamentos simultâneos, mal dimensionáveis nas imagens. Há motivo para se pensar que os desmatamentos estāo aumentando rapidamente. Não se trata apenas de um problema tecnologico: o desmatamento é um problema real, mesmo que existam diferenças nos dados obtidos com diferentes metodologias. Na imagem considerada, ocorre, ainda, um fato importante: é a penetração do desmatamento ao longo da Rodovia BR-3429, no Vale do Rio Guapore, uma área que consideramos totalmente infértil para agricultura.

Em Rondônia, o desmatamento está aumentando rapidamente, fato que redunda numa perda muito grande. Está havendo perda de toda a floresta, com todas as especies nela contidas. Mais do que isso, está se perdendo a oportuni-

Em Rondônia, n desmatamento está aumentandn

rapidamente, fato que redunda numa perda muito grande. Está havendo perda de toda

a floresta, com todas as espécies nela contidas. Mais do que isso, está se perdendo a oportunidade de se usar a floresta como recurso renovável. dade de se usar a floresta como recurso renovável. Para não aludir a outras graves conseqüências ambientais. Um dos problemas $e ́$ a sustentação e a permanência da agricultura nesses lugares, depois do processo de desmatamento. Um dos impedimentos para isso $\epsilon$ a erosão do solo, depois do desmate. É o que estamos estudando com uma calha adequada, dotada de uma tampa que se fecha, incluindo uma lâmina que fica inserida no solo e uma tubulação que sai por baixo. Esse aparelho simples é montado no solo, de modo enterrado, com a tubulação em subsuperfície. Colocada em um ponto da vertente, ela coleta toda a água das enxurradas. Uma calha instalada em área recentemente derrubada com uma cerca de $10 \mathrm{~m} \times 1 \mathrm{~m}$ - coleta a água que tomba dentro dela, a qual corre pela tubulação, ou então se evapora e volta para a atmosfera. Os lençóis coletados pela calha descem para uma série de tambores, onde se deposita toda a água e os sedimentos nela contidos. Temos estudos sobre erosão dos solos em 
áreas diversas da Amazônia: uma calha montada nos arredores de Manaus, outra na Transamazónica (Para), outra, ainda, em Rondónia e, mais recentemente, uma em Roraima. Possuímos dados de três anos em Manaus. Ficou demonstrado que ocorre muito mais erosão do solo nesses dois tipos de pastagens, do que nas áreas florestadas. Tem, mais ainda: no solo nu, como já se previa, a erosão É muito mais forte. $O$ importante $\epsilon$ saber que a pastagem também tem bastante erosão. Nos dois anos seguintes de observação nas calhas, houve valores menores, porem ainda muito acima dos valores obtidos nas áreas de matas, quando cotejadas com as pastagens. Fato que $\epsilon$ frontalmente contra a presunção de todo o planejamento de desenvolvimento da Amaz6nia, baseado em algumas premissas do Projeto RADAM BRASIL.

No volume 16, do Projeto RADAM - que se refere a Rondónia - encontra-se uma classificação dos solos regionais, segundo a classificação que norteia o proprio Projeto. No sistema de classificação proposto, considera-se que os terrenos regionais, com forte susceptibilidade à erosão, não têm condiçōes para o emprego daquele maquinário agrícola, comum à agricultura do País. Em outras palavras, está escrito que os terrenos são acidentados demais para uso do trator. Deduz-se, dar, que esses terrenos seriam proprios para pastagens cultivadas ou melhoradas, já que o seu uso, com agricultura, em qualquer sistema de manejo, as degradaria. $O$ que equivale dizer que, sob pastagens, elas ficariam degradadas. As pastagens seriam, então, apropriadas para lugares susceptíveis a erosão. Infelizmente, parece que a presunção desse critério de classificação $\epsilon$ questionável. É muito importante que, no novo zoneamento agroecológico - a ser feito de acordo com a Constituição -, não sejam adotados critérios como esse, o qual conduziria à ampliação de pastagens, as quais ficariam mal sustentadas.

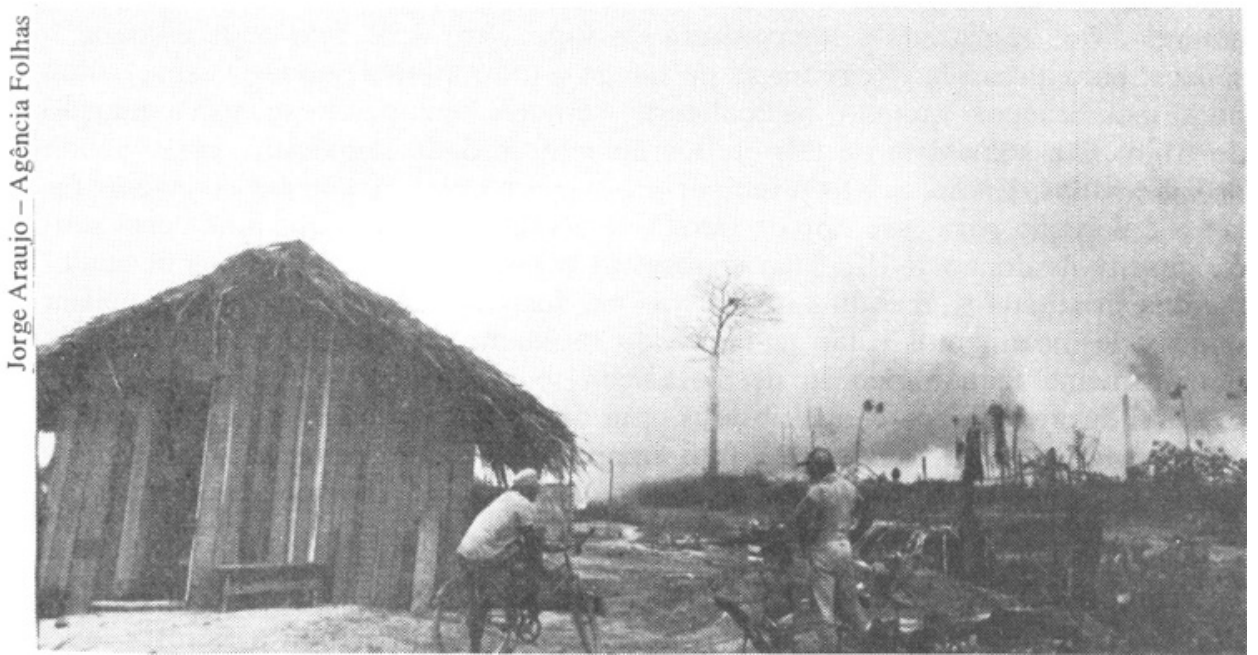

O que acontece é o seguinte: ocorre uma diminuição da quantidade de fósforo disponível no solo. Com a queimada da floresta, no primeiro momento, há um certo aumento desse teor. No entanto, ao longo de uma década, a quantidade de fósforo disponf́vel diminui sensivelmente. Esses são antigos dados da EMBRAPA - do início da década de 70 - justamente quando a EMBRAPA estava sustentando a tese de que a pastagem melhorava o solo na Amazônia. Centrada nessa idéia, subsidiava-se a formação de pastagens. Em outras palavras, removiam-se florestas para colocar pastagem. Note-se, porkm, que os próprios dados da época mostravam que o solo degradava em termos de fósforo, 0 que conduziria à queda da produção do capim.

É muito importante avaliar corretamente se são viáveis ou não as propostas atuais de sustentar grandes áreas de pastagens na base de adubação, por acrescimos de produtos fosfatados nos solos preparados para pastos. Um mapa 
organizado pelo Departamento Nacional de Produção Mineral (DNPM) mostra a distribuição das jazidas de fosfatos, no Brasil. E, como se vê, é um mapa do Brasil muito estranho, porque está faltando a metade do País. Isso ocorre porque, basicamente, não existem fosfatos na Amazônia. Os fosfatos do Brasil estăo localizados na área de Minas Gerais e vizinhanças, portanto, muito longe da Amazónia. Depois da publicação desse mapa, foi descoberta mais uma jazida, em Maecuru, no Pará, a qual está ainda sendo medida. Mas, basicamente, continua a verdade de que não existem grandes jazidas de fosfatos na Amazônia. Aliás, todo o Brasil não é muito bem dotado de fosfatos. O Relatório do DNPM indica, por exemplo, que os Estados Unidos têm 20 vezes mais jazidas de fosfatos do que o Brasil. Torna-se importante que esse fosfato seja usado para as coisas que vão ter maior produção. E, 6 certo, que a melhor escolha seja a de não se tentar sustentar, durante anos seguidos, grandes áreas de pastagens na Amazônia. E, inclusive, é necèssário encarar todo o custo do transporte desse fosfato para longínquos setores da Amazônia. A melhor opção nos parece outra. A garantia da funcionalidade dos ecossistemas naturais redunda em uma adubação constante. Não há melhor opção do que aquela que implique na manutenção de grandes áreas da propria cobertura da floresta. A produção de capim, por todas essas razões - esgotamento do fósforo, erosão, compactação do solo, entre outras - vai caindo. Nós estamos realizando mensuraçōes sobre essa questăo em diferentes áreas da Transamazônica e de Rondônia. Para tanto, usamos amostragens e fazemos medidas, dentro de uma metodologia e de técnicas rigorosamente científicas.

Nossos primeiros resultados indicam que, na Rondônia, uma pastagem com 3 anos produz o dobro do capim do que uma pastagem $\operatorname{com}_{i} 12$ anos. Isso significa dizer - por todas essas razões somadas - que hă uma flagrante diminuição de pastagens. E que o processo redunda em uma perda do seu caráter auto-sustentado. Torna-se evidente que o benefício de se cortar a floresta para uma atividade temporária é muito pequeno; além de implicar em grandes custos, com retorno relativo, a médio prazo. Um outro fato que estamos estudando é a contribuição de desmatamento para o efeito estufa, na Amazônia. Para isso, contamos com os informes das conseqüências das queimadas na região de $\mathrm{Ma}$ naus. Estudamos, também, em Altamira, na Transamazônica. Foram levantadas informações disponíveis sobre outras áreas, em termos de quantidade de biomassa da floresta. A área estudada, próxima a Manaus, demonstra que, depois da queimada, resta muita madeira no chão. Medimos quanta matéria foi transformada em carvão, cinzas, entre outros subprodutos. Convém lembrar, porém, que essa madeira também desaparece, no decorrer de uma década. Ou permanece queimada, na requeima das pastagens; ou, então, apodrece e, da mesma forma, acaba sendo lançada no ar, em forma de $\mathrm{CO}_{2}$ e Metano e outros gases: conjunto esse que contribuirá para o efeito estufa. Também uma parte do Carbono, no solo, sofre o mesmo destino.

Nós medimos a quantidade de biomassa, antes e depois das queimadas, e fizemos outras estimativas, tendo por base o volume de madeira.

Calcula-se que, para a Amazônia legal, considerando todos os tipos de vegetação, se todo o espaço florestado fosse transformado em pastagens, a quantidade de Carbono que seria lançada na atmosfera somaria mais ou menos 50 bilhōes de toneladas. Se a Amazônia fosse totalmente desmatada ao longo

Se a Amazônia fosse totalmente desmatada ao longo de 50 anos (avaliação não-fantasiosa, caso continue a progressão afual do desmate), isso corresponderia a lançar 1 bilhão de toneladas de Carbono por ano na atmosfera. de 50 anos (avaliação não-fantasiosa, caso continue a progressão atual do desmate), isso corresponderia a lançar 1 bilhão de toneladas de Carbono por ano. $\mathrm{E}, \mathrm{ja}$ que são 5 ou 6 bilhões de toneladas, anualmente, jogadas pela queima de carvão e petróleo em todo o mundo, somente o desmatamento da Amazônia representaria, potencialmente, aproximadamente, $20 \%$ do volume global, não contando o restante do desmatamento no mundo. Penso que se considerarmos todos os fatores de liberação de Carbono no mundo, a Amazônia $\epsilon$, potencialmente, um grande contribuinte em termos da taxa atual de desmatamento. De modo algum, atinge, atualmente, o nível de $20 \%$ do total. Sua contribuição po- 
de ser avaliada em 5 a 6\%; e năo 20\%. Ainda assim, porem, trata-se de uma grande contribuição no efeito estufa. Tambem há que se lembrar que as queimadas de matas são diferentes das queimadas dos combustíveis fósseis, que lançam mais Metano em relação ao Gás carbónico. E o Carbono possui um impacto maior sobre o efeito estufa. Nesse'caso, o impacto é ainda maior do que as toneladas de Carbono possam indicar em relação ao desmatamento.

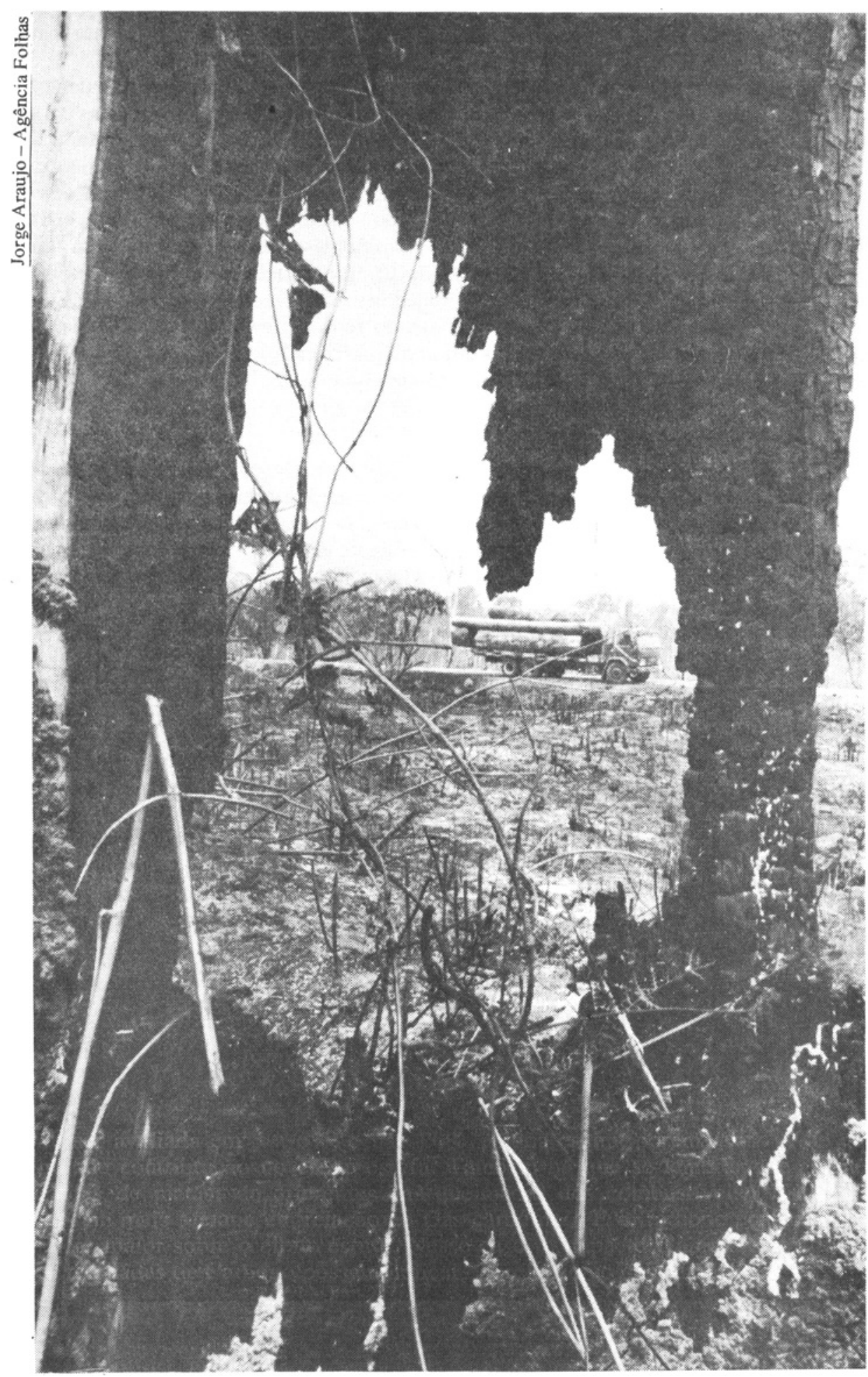


O outro grande impacto do desmatamento é o que atinge o ciclo hidrol6gico e o regime das chuvas na Amazônia e regiōes vizinhas, podendo afetar áreas distantes, inclusive São Paulo. Em nossas quadras de medida de erosão, em Rondônia - em pastagens - utilizamos 4 tambores só para apanhar a água que escorre num pequeno espaço de $10 \mathrm{~m}^{2}$. Adota-se essa área tão reduzida para não transbordar os tambores. Toda a água que cai acaba se projetando no escoamento superficial, entrando nos igarapés; não entra no solo para se tornar disponível para as raízes das árvores, que a sugaria e a devolveria novamente para $o$ ar. Um tambor é suficiente para fazer a tomada de toda a água que sai da quadra; e, muitas vezes, só há um balde suspenso, dentro do tambor. A diferença é marcante na quantidade de águá que sai pela superfície. $O$ primeiro ano de dados obtidos em Manaus indicou que a quantidade de escoamento na pastagem é da ordem de 10 vezes mais do que na floresta. Então, é uma ordem de grandeza muito diferenciada.

E, quando se pensa na escala da Amazônia, isso implica em impactos ate globais. Temos que nos lembrar que a Amazônia brasileira comporta uma área de 5 milhōes de $\mathrm{km}^{2}$, sendo que, na somatória de todos os espaços, envolve muita água, que acaba reciclada pela floresta. Possuímos medidas pontuais mais grosseiras, representadas pela simples comparação entre a vazão do rio Amazonas e a quantidade de chuva que cai, medida pelos pluviômetros que se mantêm nos aeroportos espalhados pela região. É mais facilmente medido em Óbidos, parte mais estreita do rio Amazonas, que não envolve toda a Bacia, mas uma boa parte dela. $\mathrm{E}$, comparando a água que escoa por ano, pelo rio, com a que tomba como chuva, e quase exatamente o dobro. Em outras palavras, o volume d'agua que cai como chuva, comparado com aquilo que saiu pelo rio, indica que a outra metade voltou para o ar, em vez de sair pelo rio. $\mathrm{E}$, quando se utiliza a informação de que existe uma ordem de 10 vezes a quantidade de água que sai dessas áreas desmatadas, pode-se avaliar a imensidão de água que está em jogo. É muito importante lembrar a escala desse fato, em termos do rio Amazonas. Esse grande rio, na altura do encontro das águas, perto de Manaus, o Amazonas já é um rio imenso. As medidas feitas através de todo o rio mostram seu enorme volume d'água. Mas é a mesma quantidade de água que se vê no rio Amazonas que está voltando para o ar, através das folhas, sendo que $50 \%$ ninguém vê. É uma coisa muito fácil para qualquer pessoa verificar; basta colocar um saco plástico em volta de um galho com algumas folhas e, dentro de poucos minutos, estará tudo suado por dentro, com gotinhas d'água. Aquilo é água saindo das folhas que, somada com bilhões de águas similares na Amazônia, representam o rio Amazonas. Então, essa água é muito importante para manter o ciclo hiđrológico na regiāo. A água é transportada em forma de nuvem: uma parte vem do Oceano Atlântico, e, outra, é proveniente do bombeamento pelas árvores. E, medidas das razões de radioisótopos nessa água, feitas pelo grupo do Salatti, indicam que $50 \%$ ficam reciclados pela floresta na região entre Belém e Manaus. Essas medidas indicaram, também, que existe uma diferença em relação ao distanciamento do mar: a participação da floresta é maior em Manaus do que em Belém; a média é que atinge 50\%. Então, logicamente, afastando-se mais do mar, a floresta torna-se mais importante como reservatorio d'água. E, chegando ao Acre ou Rondônia - que é justamente o lugar onde tem o maior surto atual de desmatamento - a importância da floresta seria muito maior do que 50\%. É fácil deduzir que essas áreas iriam sofrer maior impacto de desmatamento sobre o clima. Esse fato é confirmado por vários outros estudos, inclusive o transporte da água para outras regióes. Registro, aqui, dados publicados, de simulação por computador, da circulação global (clima global) feita pelo Instituto Goder de Estudos Espaciais, em Nova York. Essa pesquisa indicou que a massa de umidade que começa na Amazônia projeta-se depois, como chuva, em toda uma imensa região do Planalto Brasileiro. Então, atinge, por exemplo, São Paulo, a parte mais produtiva em termos agrícolas do Brasil 
de hoje. Outros dados tambem confirmam isso. Na observação do movimento das nuvens, por satélites meteorológicos - aquelas fotografias que saem no jornal todo dia - pode-se ver o movimento das nuvens. Observa-se a seqüência em que cada massa de nuvens formadas sobre a Amazônia muda de trajeto em certas altitudes, sendo transportada para a região de São Paulo e Paraná, as partes mais produtivas do Brasil. Esse é um exemplo de como o desmatamento da Amaz6nia pode afetar a agricultura no resto do País.

Outro fato muito importante sobre a ciclagem hidrologica, talvez mais importante do que o dado grosseiro de $50 \%$ de chuva, $\epsilon$ a diferença entre a época seca e a época chuvosa. Os dados disponíveis, sobre o vapor d'água, indicam que a floresta é mais importante durante a época seca. É muito mais fácil entender porque isso ocorre. Na época seca, as pastagens ficam em degenerescência periódica. As folhas do capim morrem, e elas não têm capacidade de transportar a água e, portanto, de devolver a água para o ar; enquanto, nas áreas florestadas, a vegetação permanece verde durante $o$ ano inteiro, $o$ que significa que ela continua bombeando água também na época da seca. Isso implica em prever a possibilidade do aumento do perigo de ter supersecas, de quando em vez, na Amazônia.

Existem dados de 31 anos, para Altamira, na Transamazónica, que indicam a chuva mensal, a média mensal, e um desvio-padrāo. Esses dados indicam a existência de uma tremenda variação, de um ano para outro, na quantidade de chuva que cai. E, nas Épocas de estiagem, $€$ muito fácil de se observar o prolongamento de um periodo seco, o qual, via de regra, $\epsilon$ de um mês a mais, um mês a menos; mesmo sem desmatamento. Os desmatamentos, em grande escala, aumentam essa variabilidade, ocorrendo mínimo de chuva de estiagem, aumentando muito o perigo de ocorrer secas muito mais longas do que as atuais: um prejuízo potencial não só para a agricultura, como também para a sobrevivência da própria floresta. Temos já os primèiros resultados de um estudo que está sendo feito ao norte de Manaus - nas fazendas, no distrito agropecuário da SUFRAMA - no projeto WWF e INPA, numa area onde ocorrem ilhas de matas deixadas no meio das pastagens. Existem, aí, mais de 80 mil árvores, todas com etiquetinhas de alumínio; o conjunto sendo mapeado e seguido, para se ver quando cada árvore morre, como é que morre, entre muitas outras observações. Já se observou que, nas matas, as árvores situadas em beiradas das reservas morrem muito mais rapidamente do que aquelas que estão mais interiorizadas. Esse seria um efeito do ressecamento - do stress hidráulico - que essas árvores estão sofrendo. Aconteceria o seguinte: com a abertura da copa da floresta, com a morte das árvores, isso acarreta, a nível regional, uma diminuição da chuva, fato que implica ainda em mais ressecamento na floresta, mais mortalidade de árvores e, logo, mais aberturas no dossel das florestas. Também, a nível local, expóe a floresta para a entrada direta do sol e do vento, ressecando mais o conjunto. E, ar, ocorrem dois círculos viciosos de degenerescência florestal. Trata-se de um fenecimento diferencial. Nas reservas do WWF, onde árvores, na beirada, muitas vezes, morrem em pe. Esse fato indica que não são puxadas por cipós ou outras coisas para provocar a morte. Seria mais provável por causa do ressecamento do microclima nesses lugares, uma coisa facilmente perceptível, para quem caminha da derrubada para dentro da floresta. Existe um perigo nesse tipo de disclímax, que $\epsilon$ o desvio da sucessão ecologica: no caso, ao inves do retorno para algum tipo de floresta com árvores, de se caminhar para tipos de gramíneas. Numa pastagem degradada no Acre, em solos muito degradados, ao invés de retomarem embaúbas, numa vegetação secundária, entraram espécies de andropolos, chamadas de rabo-de-cavalo, que se alastram especialmente em solos degradados. Trata-se de um tipo de ocorrência muito mais comum na Ásia do que na América do Sul. No caso, ao invés do retorno da floresta, sucedem-se gramíneas invasoras: um fato que deve estar relacionado ao ressecamento do clima, e que aumenta muito o impacto do desmatamento, tanto sobre o ciclo das chuvas como também sobre o efeito estufa. E, esses desmata-
(...) com a abertura da copa da floresta, com a morte das árvores, isso acarreta, a nfvel regional, uma diminuição da chuva, fato que implica ainda em mais ressecamento na floresta, mais mortalidade de arvores e, logo, mais aberturas no dossel das florestas. 
mentos, que vêm aumentando por diversas razões, fazem fenecer a biomassa, favorecendo o ingresso de plantas daninhas.

Identificando essas distorções, podem se fazer propostas para reverter a situação e ver como é que poderiam ser controladas. Um dos fatores é o incentivo oficial dado às fazendas de pecuária, na região amazônica. No distrito agropecuário de Manaus, onde existem incentivos especiais para derrubar e plantar pastagens, ocorreu um fato importante para o controle: foi suspensa por 90 dias a concessão de novos incentivos, com o pacote chamado Nossa Nature$z a$. Acho necessário fazer de uma vez o corte desses absurdos incentivos. E dar um fim aos incentivos antigos, que favorecem a implantação de centenas de fazendas, com projetos aprovados, que continuam recebendo o dinheiro de incentivos. No mínimo, haveria que se rever esses projetos, redirecionando-se para reflorestamento ou outra atividade que não seja desmatamento. Também, existem outros tipos de incentivos, como aqueles para ferro gusa, em Carajás. $E$, para serrarias, as quais não entram na suspensão de incentivos do programa Nossa Natureza.

O Programa Grande Carajás, que envolve $900 \mathrm{mil} \mathrm{km}^{2}$, é uma área com muitos tipos de incentivos especiais. E, o problema mais grave do chamado PPC é o problema da fabricação de ferro gusa, a partir do uso de carvão de madeira.

A primeira usina de ferro gusa em Açailândia, no Maranhão, começou no dia 8 de janeiro de 1988. Nenhuma das usinas de ferro gusa tiveram obrigatoriedade de um relatório de impacto do meio ambiente, fato obrigatório desde janeiro de 1986. Então, é muito importante que todo o tipo de projeto seja estudado, em termos do seu impacto ambiental, fato que, no caso o fabrico de ferro gusa a carvão vegetal deve ser muito grande. Registro o fato que se iniciou em março deste ano (1988), a produção de ferro gusa na área de Marabá. Tenho fotos que mostram os lingotes do ferro gusa sendo obtidos pelo uso de carvão vegetal, provenientes das árvores da floresta. $O$ carvão fabricado em fornos de modelo comum $\varepsilon$ feito em centenas de fazendas existentes no entorno do Distrito Industrial de Marabá. Nestas circunstâncias, torna-se muito difícil o controle do desmatamento por parte do Governo. E, como se vê nas fotos, o carvão E fabricado com madeira roliça da floresta; não se trata de restos de serraria, conforme declaraçōes das indústrias de ferro gusa. Por outro lado, pode-se adiantar que o crescimento do uso de carvão será constante. E esse carvão somará uma grande quantidade; mesmo porque a quantidade de ferro em Carajás é de 18 bilhōes de toneladas. Trata-se de uma quantidade infinita em relação à capacidade da floresta Amazônica em suprir indústrias siderúrgicas com carvão de madeira. Somente com as 2,8 milhōes de toneladas de ferro gusa, atualmente aprovadas, seriam necessários $1.000 \mathrm{~km}^{2}$ ao ano, ou seja, 100 mil hectares de terras florestadas para suprir os fornos de carvão vegetal. Sem falar que existem outros projetos de ferro-liga, cimento e sílica, na área, os quais também pressupõem o uso desse tipo de carvão. O zoneamento da SUDAM, em relação à área, para produção de carvão vegetal para suprir o Programa de Carajás envolve o destino de uma área imensa. Prevê-se a utilização de um espaço equi-

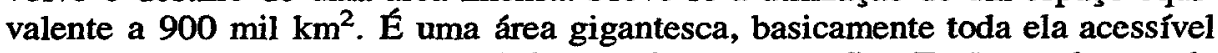
por transportes e que permanecerá zoneada para esse fim. Então, o alcance da depredação será muito grande. Trata-se de um processso que irá, potencialmente, abocanhando a floresta, ao longo do tempo, devido à natureza do programa industrial implantado, que é praticamente permanente para a regiāo.

Outro fato que está ocasionando mudanças rápidas no quadro do desmatamento regional é o aumento do número de serrarias. Até há pouco tempo, esse era um fator insignificante no desmatamento da Amazônia. Desde 1983, entretanto, mais ou menos, o preço da madeira nos mercados internacionais vem subindo rapidamente, sọbretudo em função de estarem acabando as últimas flo- 
restas no sudēste da Asia. Essas florestas da Asia ainda estão produżindo mas, quando realmente se findarem, haverá um extraordinário surto de desmatamento na Amazônia. Processo que, de resto, ja se iniciou pela montagem de milhares e milhares de serrarias, a cada ano, na região. Trata-se de um novo impacto na devastação das selvas amazônicas.

Antigamente, a madeira era explorada só na base artesanal. Atualmente, o processo é bem mais mecanizado, com o uso de moto-serras. O grosso dos procedimentos é ainda rotineiro, envolvendo o corte de tora por tora. Mesmo assim, a floresta resta em uma situação muito mais frágil, após o desmate. Em Rondônia, como pudemos observar, o sub-bosque fica completamente destruído. Muitas árvores, além daquelas de madeira nobre já removidas, ficam seriamente danificadas. Com isso tudo, as florestas ficam muito mais susceptíveis à entrada de fogo. Identicamente, as queimadas anuais de pastagens acabam por atingir grandes trechos de florestas. Trata-se de um ponderável fator complementar para acabar com os restos de florestas que não são desmatadas de vez. Essa combinação de processos predatórios já aconteceu, em Borné, em 1983, onde se queimou 3 milhões de hectares de florestas, ainda em pé.

Normalmente, na Amazônia, tem que se derrubar a floresta, esperar sua secagem, para depois poder queimar. Entretanto, com as mudanças esperadas no regime de chuvas, através da generalização do desmatamento, $\epsilon$ muito provável que nos próximos anos - talvez cada 20 ou 50 anos - por ocasião de estiagens mais fortes, o fogo se ampliará dentro da floresta, num processo catastrófico similar ao que acontece na América do Norte, na Europa e outros países, onde não é necessário desmatar para depois queimar a floresta. Nesse caso, o processo se acelerará, afetando muito mais áreas florestadas do que se possa imaginar. Atualmente, estamos relativamente protegidos, pelo fato de que só algumas espécies estão sendo exploradas pela indústria madeireira; por exemplo: o mogno, em Rondônia. O grosso da lista de espécies da floresta não está sendo atingido. Mas isso, também, é uma coisa que facilmente pode mudar. Como, por exemplo, o caso da exportação de toras para a China, que náo pressupõe qualquer seleção de espécies. Observa-se o fato, tanto em portos fluviais do Amazonas quanto no rio Madeira, sobretudo na Rondônia. Na Rondónia carrega-se cada 15 dias um navio com toras heterogêneas; e se leva todas as especies. Essa é uma exceção aberta para exportar madeira em toras, das usinas hidroelétricas: no caso, a usina de Samuel. O problema é que, na China, basicamente, não existe madeira. Daí o fluxo, em progressão de toras, indo para serrarias da China. Não dá para imaginar o que acontece nas serrarias da China. Tenho uma foto em que estão serrando madeiras de péssima qualidade: toras tortuosas cheias de nós, para fazer tábuas. Material que, aqui, seria jogado no lixo, no ato; ou, então, seria encaminhado para o fabrico do carvão, ou coisa parecida. A abertura do comércio de toras é um problema que, potencialmente, poderia ter muito mais impacto na exploração madeireira da Amazónia, na medida em que aumentaria o número de espécies atraentes para exploração. Inclusive, um dos problemas, atualmente, pouco visível na Amazônia, mas muito comum na Ásia, é a trituração da floresta para fazer cavacos. Para o desmatamento da área de inundação da hidroelétrica Balbina, perto de Manaus, foi feita uma primeira experiência nessa direção. Fato muito comum, também, de se ver na Ásia. Por exemplo, na Nova Guiné, há uma técnica chamada de aproveitamento total da floresta, feita por firmas japonesas - ali instaladas - as quais simplesmente tomaram uma floresta tropical inteira, trituraram e colocaram no navio, levando-a para o Japão, para fazer compensado, papelāo e outros produtos; coisas tecnicamente viáveis. Trata-se de um processo que, até agora, não entrou com grande pressão na Amazônia. Mas $\epsilon$ um procedimento que facilmente pode ocorrer no futuro. Inclusive, porque existe a possibilidade de uma grande procura de madeira picada, quando acabarem os estoques de petróleo no mundo. Em qualquer caso, a pressão sobre a floresta amazônica tenderá sempre a aumentar, através dos mais diversos procedimentos. 


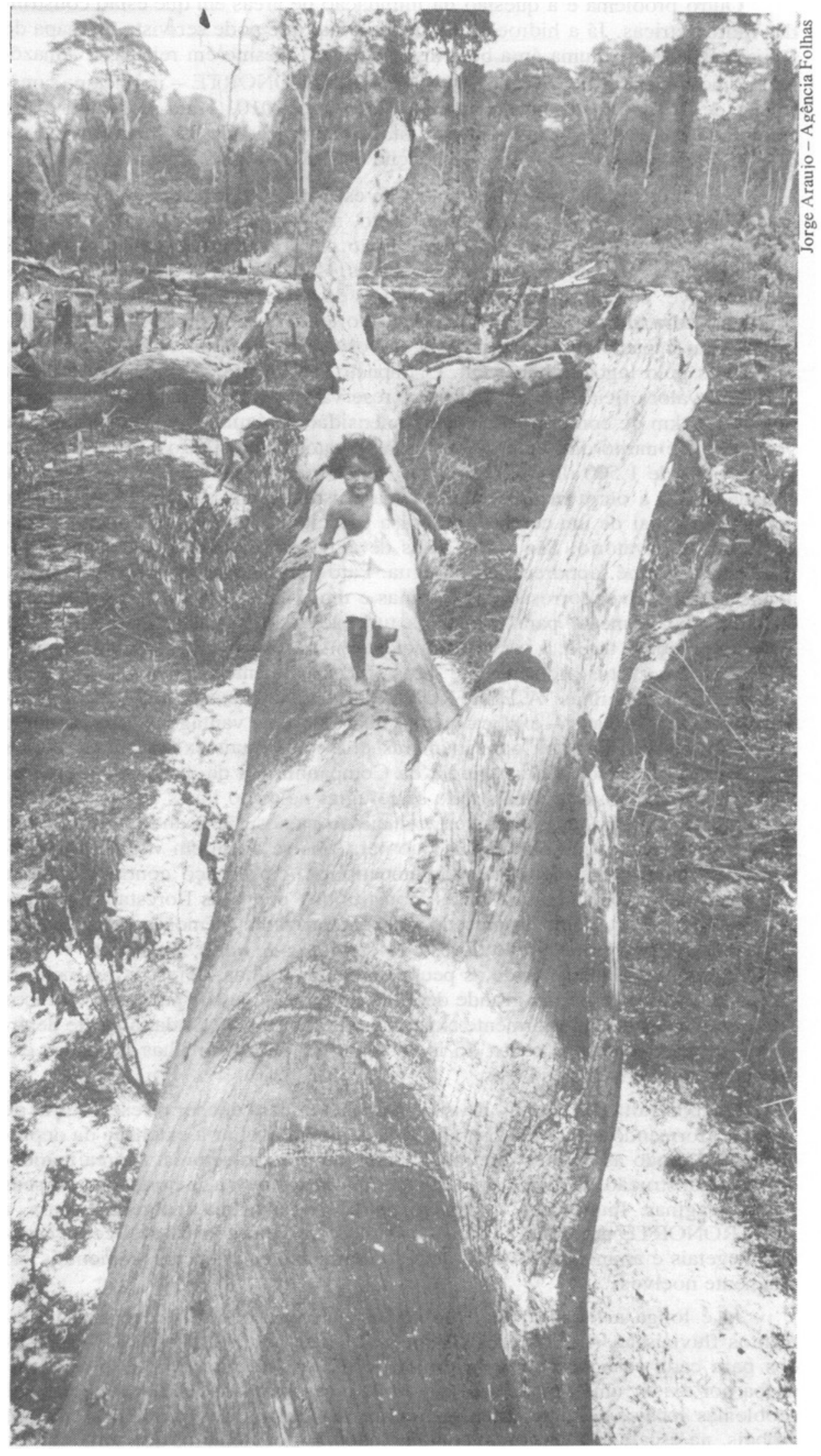


Outro problema é a questão da inundação de áreas em que estão construídas hidroelétricas. Já a hidroelétrica de Balbina, que pode ser vista no mapa do Projeto RADAM, é uma área bem insignificante, mesmo em relação à Amazônia, como um todo. E, o Plano 2010 - da ELETRONORTE - implica na construção de 76 barragens na Amazônia, até o ano 2010. Trata-se de um plano anunciado em 1985, em que era prevista a construção de 85 barragens na região. O Plano 2010 pressupõe a inundação de 2\% da regiâo Amazônica.

Vários dos problemas que aumentam esse impacto ainda mais são evidentes no caso de Balbina, construída ao custo, no mínimo, de 750 milhōes de dólares - provavelmente, mais que um bilhão - para produzir uns míseros 100 megawatts, no máximo, destinados a Manaus. Uma iniciativa quase desnecessária, inclusive, porque, apenas 6 anos depois de começar a funcionar, será construída a futura hidroeletrica de Cachoeira Porteira, que suprirá Manaus, amplamente. Um impacto ambiental imenso, envolvendo $2.360 \mathrm{~km}^{2}$, de áreas a serem inundadas pelo lago da barragem. $O$ impacto, realmente, é ainda muito maior do que o valor oficial. Observando-se o reservatório de Balbina (que, por sinal, possui $150 \mathrm{~km}$ de comprimento - uma imensidão de águas represadas), pode-se ver que ele é muito diferente de outros reservatórios brasileiros. $O$ reservatório vai ter mais de 1.500 ilhas. Ou seja, ele vai ser um mosaico de terras e águas: a metade, terra; a outra metade, água. Uma coisa que em mapa parece mais um corte transversal de um cérebro, ou coisa parecida; mas que, no entanto, tratase de um reservatório. São todas baías de água parada, estagnada, com a floresta ainda em pé, apodrecendo na água. Fato que ocasionará uma água muito ácida, com possível corrosão das turbinas e um altíssimo custo de manutenção. Calculei que, somente para manter as turbinas, vão se gastar mais ou menos $10 \%$ do preço da tarifa, a ser estabelecida. Então, os impactos são muito grandes, além dos custos propriamente ditos, excessivamente elevados. $\mathrm{E}$ um deles é o problema das ilhas. A ELETRONORTE, na sua revista em quadrinhos distribuída em Manaus - explica que as ilhas são uma vantagem. Isso porque o lago da barragem contaria com inúmeras ilhas, nas quais existiriam condições para a preservação da vida. A idéia da Companhia é a de que essas ilhas irão diminuir o impacto: os animais indo se refugiar nelas ao invés de se afogarem. Na realidade, porém, essas ilhas estão mais ou menos duplicando o impacto do reservatório, sendo que os animais que para elas se dirigirem vão acabar morrendo, no auge dos processos intercompetitivos, em espaço contido. Sabe-se que em setores por demais restritos, constituídos por ilhas florestadas, a competição será feroz, como é mais do que comprovado. Temos a comprovação desse fato no proprio exemplo do estudo das ilhas de mata, do projeto WWF e INPE, perto de Manaus, onde as pequenas matas e ilhas, deixadas no meio da pastagem, ocasionaram um grande declínio de populações de pássaros, macacos e todas as espécies anteriormente existentes. Registrou-se, ainda, a morte de árvores, simplesmente por causa do isolamento em forma de ilhas de matas expostas ao sol por todos os lados.

Quando faltavam, ainda, mais ou menos $3 \mathrm{~m}$ para encher o reservatório de Balbina, formando o lago da barragem, já se podia avaliar a extensão da depredação, incluindo as árvores que morriam em numerosos setores. A área inundada pela construção da barragem é muito maior do que a maioria das pessoas possa imaginar. Inundou-se, inclusive, parte de uma área indígena. Agora, a ELETRONORTE apresenta o balanço total do projeto como benéfico às espécies vegetais e animais da região, quando realmente os impactos ambientais são altamente nocivos.

Já é longa a listagem dos problemas que vêm ocorrendo com os barramentos fluviais na Amazônia. Existem problemas gerais e problemas específicos para cada caso de barragem projetada. E, em se tratando de 85 projetos, acaba por existir uma grande área da região a ser inundada; cada qual com seus problemas locais, bastante diferentes entre si. Alguns dos problemas são até globais, na escala em que forem contemplados. É bom lembrar que serão $2 \%$ da
Felizmente, já existem várias propostas para uso auto-sustentável das florestas amazônicas. Por exemplo, fazendo reservas extrativistas para retirar, lentamente, produtos de valor da floresta. $E$, entre outros procedimentos, o da manutenção da própria floresta em pé, para o pleno desenvolvimento de suas funçōes ambientais. 
Amazônia a serem inundados por essas hidroelétricas. $\mathrm{E}$ também há que se levar em conta a área naturalmente inundada das várzeas amazônicas, que soma a 3\% da área total da região. A várzea amazônica é inundada sazonalmente. Foi descoberto pelo grupo da NASA, há uns 3 anos atrás, que elas são uma das grandes fontes de Metano na atmosfera. Metano é um gás, $\mathbf{C H}_{4}$, que é muito mais potente que o $\mathrm{CO}_{2}$ por tonelada, para provocar o efeito estufa. Esse é um tipo de contribuição natural da várzea, na categoria de uma das fontes a Gás Metano, na atmosfera. Imagine-se, agora, o que seria se essas áreas a serem inundadas fossem produzir Metano, à mesma taxa das várzeas; isso iria duplicar a quantidade de Metano que está sendo lançada pela região na atmosfera. Tratase de um legítimo problema de impactos globais. Além de outros impactos: sobre as áreas indígenas, sobre a floresta, impacto das linhas de transmissão, instalações para 0 acesso à ilhas, entre outras conseqüências derivadas desses projetos. Por todas essas razóes, torna-se muito importante que sejam fortalecidos os procedimentos para exame dos relatórios do impacto do meio ambiente, para nāo se repetir os tipos de problemas que estamos assistindo em Carajás, em Balbina, em Rondônia e outras áreas. E, isso, é uma das exigências da nova Constituição. Daí porque julgo que é muito importante enfrentar, de maneira enfática, tais questões, para não correr o risco dos impactos que certamente ocorrerão. Entre outros procedimentos, que necessitam ser feitos, temos que ter em mente o entendimento das verdadeiras causas do desmatamento. Nesse particular, existem coisas fáceis de se fazer. Não aceitar pastagem como benfeitoria para fins de estabelecimento de posse da terra, procedimento que eliminaria um dos grandes motivos da progressão do desmatamento na região. Desestimular ao máximo a especulação com terras: outro grande motivo de desmatamento.

Existe um forte grupo de pessoas desmatando, queimando e plantando pastagem para segurar a terra para que outros não entrem nelas, com receio dos posseiros, grileiros ou da Reforma Agrária. Ou o que quer que seja. Existe, sempre, na Amazônia, alguém tirando o lucro disso tudo. Por essa razão, há que se colocar impostos sobre os lucros de valorização das terras: um procedimento que poderia ser feito com um simples decreto, sem gastar um tostão do Governo. Outra precaução é a de não construir estradas para as áreas de solos inférteis, como foi o caso da BR-429, em Rondônia, que atravessa setores totalmente inférteis da região. E, a última recomendação, é a de cortar todos os incentivos. Não somente novos incentivos; e, não só os incentivos de pecuária. Mas, também, os incentivos para serrarias, para ferro gusa, e outros projetos. E somente utilizar florestas que sejam auto-sustentáveis.

Felizmente, já existem várias propostas para uso auto-sustentável das florestas amazônicas. Por exemplo, fazendo reservas extrativistas para retirar, lentamente, produtos de valor da floresta. E, entre outros procedimentos, o da manutençâo da própria floresta em pé, para o pleno desenvolvimento de suas funçōes ambientais. Uma proposição das mais importantes entre as que realmente importam. É absolutamente necessário o encontro de fórmulas para o uso da floresta, que não retirem as suas funçōes ambientais e a sua diversidade biológica. Para isso é que deveriam existir tipos especiais de incentivos, a fim de não perder a oportunidade única de continuar contando com os efeitos ambientais da floresta.

É certo que, a partir de muitas cabeças, estão sendo repensadas, de maneira geral, as políticas relacionadas à Amazônia. E se espera que algumas dessas mudanças possam ser feitas a tempo, antes que aquelas tendências exponenciais de desmatamento eliminem, para sempre, essas opções.

Philip Fearnside é pesquisador do INPA (Instituto Nacional de Pesquisa da Amazônia) Departamento de Ecologia, Manaus. 


\section{ANEXO \\ Bibliografia \\ Philip Fearnside sobre a Amazônia (1979-1986)}

FEARNSIDE, Philip M. The development of the Amazon rain forest: priority problems for the formulation of guidelines. Interciencia, 4: 338-343, 1979.

O processo de desertificação e os riscos de sua ocorrência no Brasil. Acta Amazônica, Manaus, 9: 393-400, 1979.

. O agroecossistema dos colonos da Transamazônica: simulação de produções de milho. Ciência e Cultura, São Paulo, 31 (7): 14, 1979. Suplemento.

The simulation of carrying capacity for human agricultural populations in the humids tropics: program and documentation. Manaus, INPA, 1979.

. Black pepper yield prediction for the Transamazon highway of Brazil. Turrialba, 1980. n 30, p. 35-42.

Land-use allocation of the Transamazon highway colonists of Brazil and its relation to human carrying capacity. In: Land, people and planning in Contemporary Amazônia. Ocasional Paper n 3, Cambridge, U.K., Centre of Latin American Studies, 1980. p. 114-138.

The effects of cattle pastures on soil fertility in the brazilian Amazon: consequences for beef production sustainability. Tropical Ecology, (21): 125-137, 1980.

. The prediction of soil erosion losses under various land uses in the Transamazon highway colonisation area of Brazil. In: Tropical Ecology and Development (...) Kuala Lumpur, International Society for Tropical Ecology (ISTE), 1980. p. 1287-95.

Deforestation and decision-making in the development of brazilian Amazon. In: Simpósio Internacional sobre a Amazônia. Belém, julho, 1983.

Brazil's Amazon forest and the global carbon problem. Interciência, $10(4), 1985$. 
. Environniental change and deforestation in the brazilian Amazon. In: HEMMING, J., ed. Change in the Amazon Basin: man's impact on forest and rivers. Manchester, U.K., Manchester University Press, 1985. p. 71-89.

Human carrying capacity of the brazilian rain forest. New York, Columbia University Press, 1986.

Previsão de produçōes de cacau na rodovia Transamazônica. Ciência e Cultura, São Paulo, 36 (7), 1984. Suplemento.

- A floresta pode acabar? Ciência Hoje, São Paulo, 2 (10), jan./fev. 1984.

Brazil's Amazon settlement schemes: conflicting objetives and human carrying capacity. Habitat International, 8 (1): 45-61, 1984.

Initial soil quality conditions on the Transamazon highway of Brazil and their simulation in models for estimating human carrying capacity. Tropical Ecology, 25 (2), 1984.

Land clearing behavior in small former settlement schemes in the brazilian Amazon and its relation to human carrying capacity. In: CHADWICK e SULTAN., eds. Tropical rain forest: ecology and management. Leeds Philosophy and Literature Society, Leeds, U.K., 1984. p. 255-71.

FEARNSIDE, P.M. e RANKIN, J.M. Jari and development in the brazilian Amazon. Interciência, (5): 146-56, 1980.

Jari and Carajas: the uncertain future of a large silvicultural plantations in the Amazon. Interciência, 7 (6): 326-328, 1982.

. The new Jari: risks and prospects of a major Amazonian development. Interciêncị, 7 (6): 329-339, 1982.

FEARNSIDE, P.M. e FERREIRA, G.L. Roads in Rondônia: highway construction and the farse of unprotected reserves in Brazil's Amazonian forest. Environmental Conservation, 11 (4): 358-360, 1984. 